\title{
Erratum to: Protected Graft Copolymer Excipient Leads to a Higher Acute Maximum Tolerated Dose and Extends Residence Time of Vasoactive Intestinal Peptide Significantly Better than Sterically Stabilized Micelles
}

Sandra Reichstetter • Gerardo M. Castillo • Israel Rubinstein • Akiko Nishimoto-Ashfield • ManShun Lai • Cynthia C. Jones • Aryamitra Banerjee $•$ Alex Lyubimov $•$ Duane C. Bloedow $•$ Alexei Bogdanov Jr. Elijah M. Bolotin

Published online: 9 May 2013

(C) Springer Science+Business Media New York 2013

\section{Erratum to: Pharm Res}

DOI 10.1007/s11095-012-0904-4

We regret that the seventh author's name was incorrectly spelled and should read as follows: Aryamitra A. Banerjee.

The online version of the original article can be found at http://dx.doi.org/ | 0. | 007/s | |095-0 |2-0904-4.

S. Reichstetter - G. M. Castillo • A. Nishimoto-Ashfield • M. Lai •

C. C. Jones • E. M. Bolotin $(\square)$

PharmalN Corp., 19805 N, Creek Parkway

Bothell, Washington 980 I I, USA

e-mail: ebolotin@pharmin.com

I. Rubinstein

College of Medicine, The University of Illinois

840 S, Wood St. (M/C 719) 920-N CSB

Chicago, Illinois 606 12, USA

I. Rubinstein

Jesse Brown VA Medical Center, Chicago, Illinois 60612, USA

A. Banerjee $\cdot$ A. Lyubimov

College of Medicine, The University of Illinois

808 S. Wood Srteet, Rm. 1306

Chicago, Illinois 60612, USA

D. C. Bloedow

School of Pharmacy, The University of Washington, $\mathrm{H}-272$

Box 3576I0, Seattle, Washington 98I95-763I, USA

A. Bogdanov Jr.

University of Massachusetts Medical School, Worcester

Massachusetts, USA 